Supplement of Biogeosciences, 14, 4965-4984, 2017

https://doi.org/10.5194/bg-14-4965-2017-supplement

(C) Author(s) 2017. This work is distributed under

the Creative Commons Attribution 3.0 License.

(c) (1)

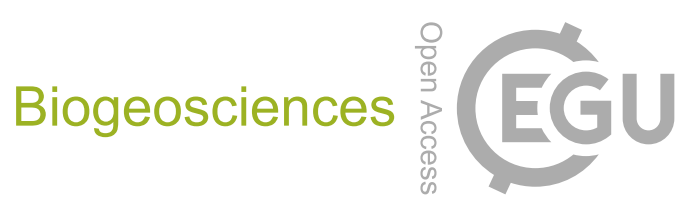

Supplement of

\title{
Calibration of a simple and a complex model of global marine biogeo- chemistry
}

Iris Kriest

Correspondence to: Iris Kriest (ikriest@geomar.de)

The copyright of individual parts of the supplement might differ from the CC BY 3.0 License. 


\section{Supplement:}

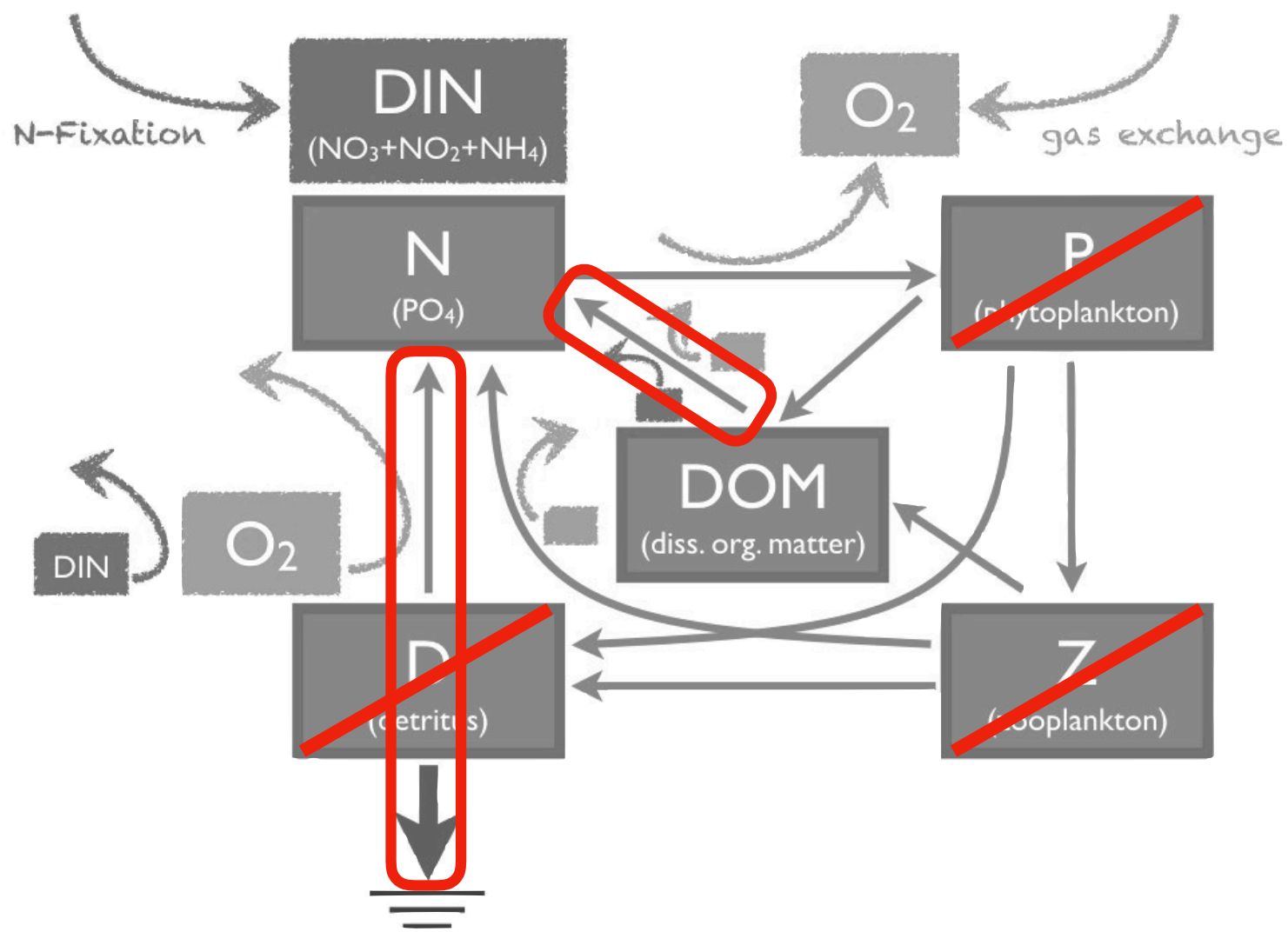

Figure S1. Diagram illustrating the changes for the downscaling of model MOPS (gray) to RetroMOPS. Omitted compartments are indicated by red diagonal bars. Structural changes for fluxes between the compartments are indicated by red borders. 


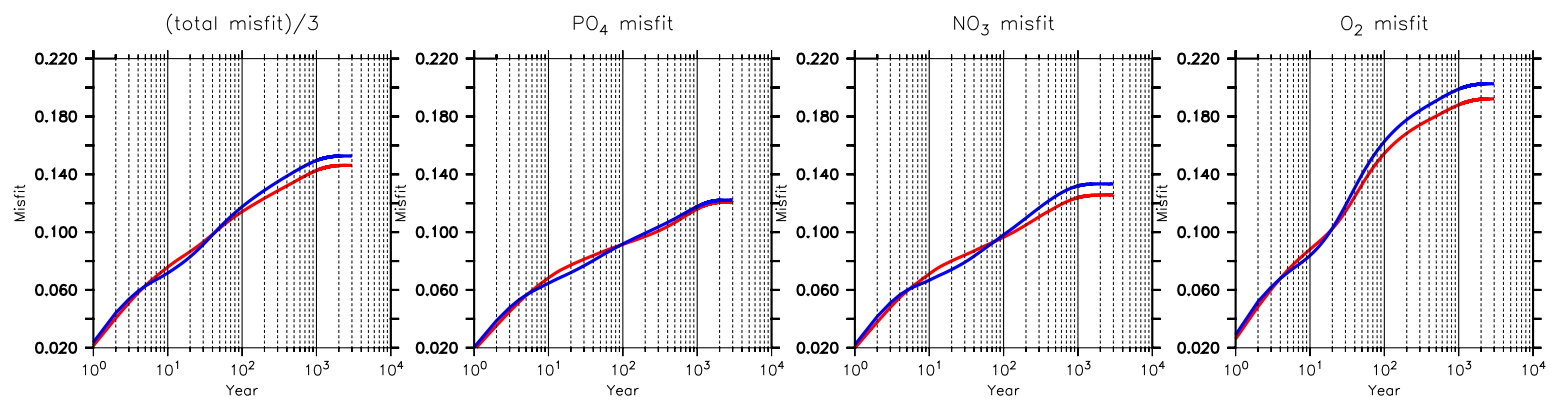

Figure S2. Model misfit of the best (final) candidate of MOPS $^{\circ D}$ (red) and RetroMOPS ${ }^{\circ}$ (blue), plotted over the entire spin-up of 3000 years (as log scale). Left panel: total misfit $J$, divided by three. Left to right panels: components (phosphate, nitrate, oxygen) of the misfit function. Note that, depending on simulation time, a different model type may exhibit the lowest misfit. 

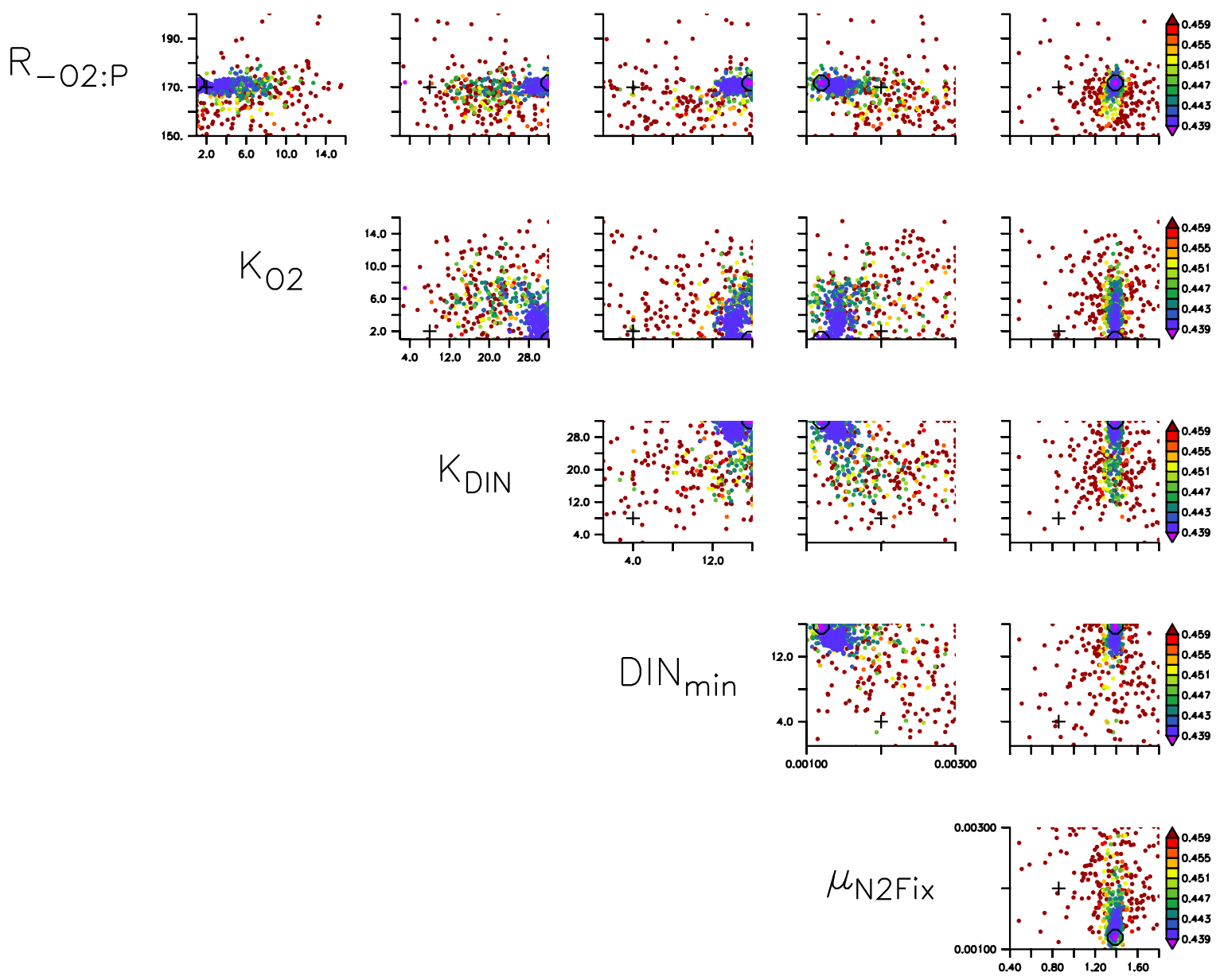

b

Figure S3. Model misfit, plotted for each pair of parameter combinations of MOPS ${ }^{\mathrm{DD}}$. Colour indicates misfit (see the colour bars on the right). A circle indicates the parameter of one individual of the last generation. For better visibility the parameter range to its boundaries (see Table 1). 

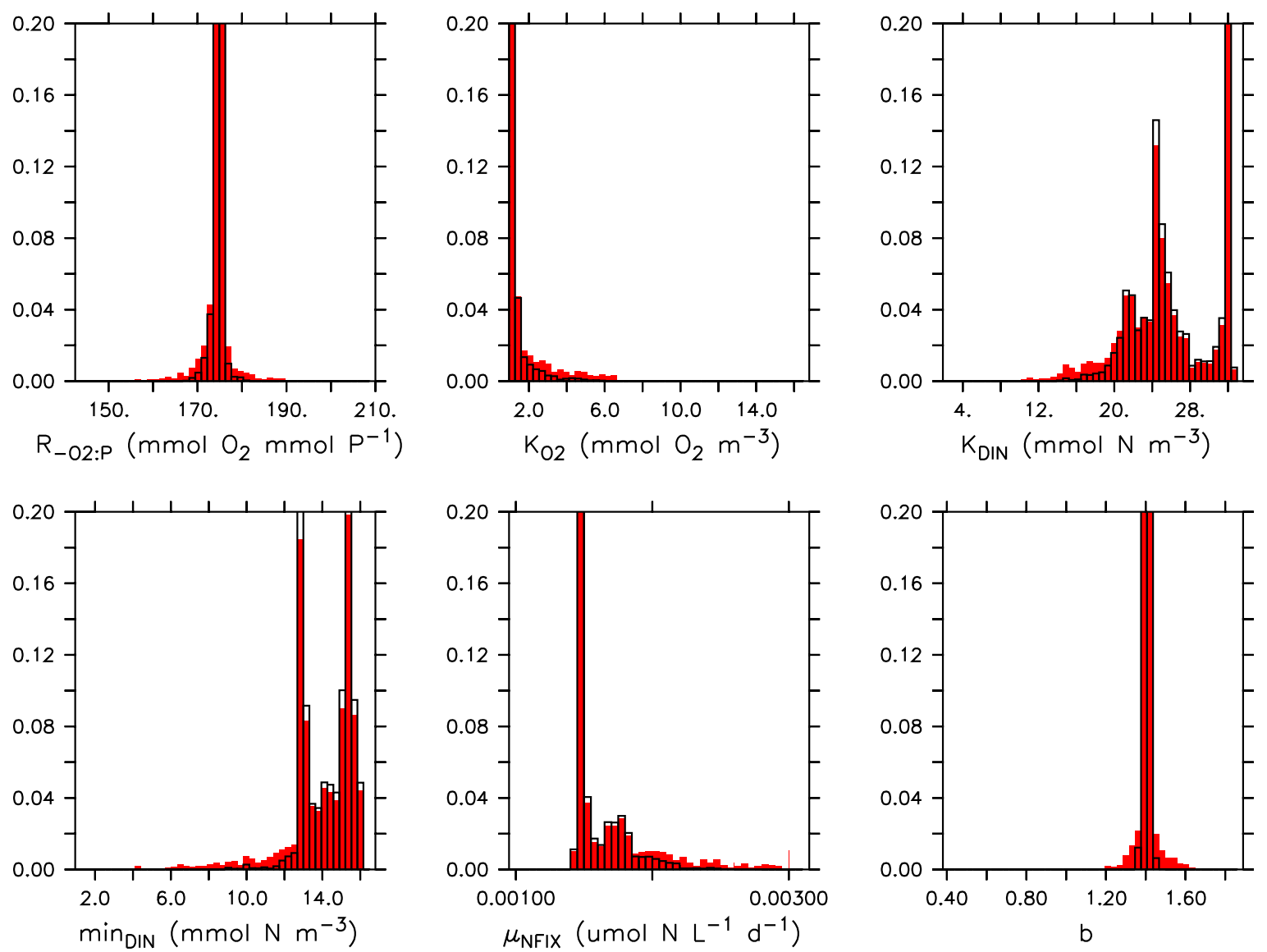

Figure S4. Parameter distribution of model simulations obtained during the optimisation of MOPS ${ }_{*}^{\text {oD }}$, whose misfit do not exceed a threshold limit of $\Delta J=1.1 J^{*}(10 \%$, red bars $)$ or $\Delta J=1.01 J^{*}\left(1 \%\right.$, open bars) of the minimum misfit $J^{*}$. For the projection parameters of all model simulations in the optimisation trajectory were grouped into 50 classes. 
Indian Ocean
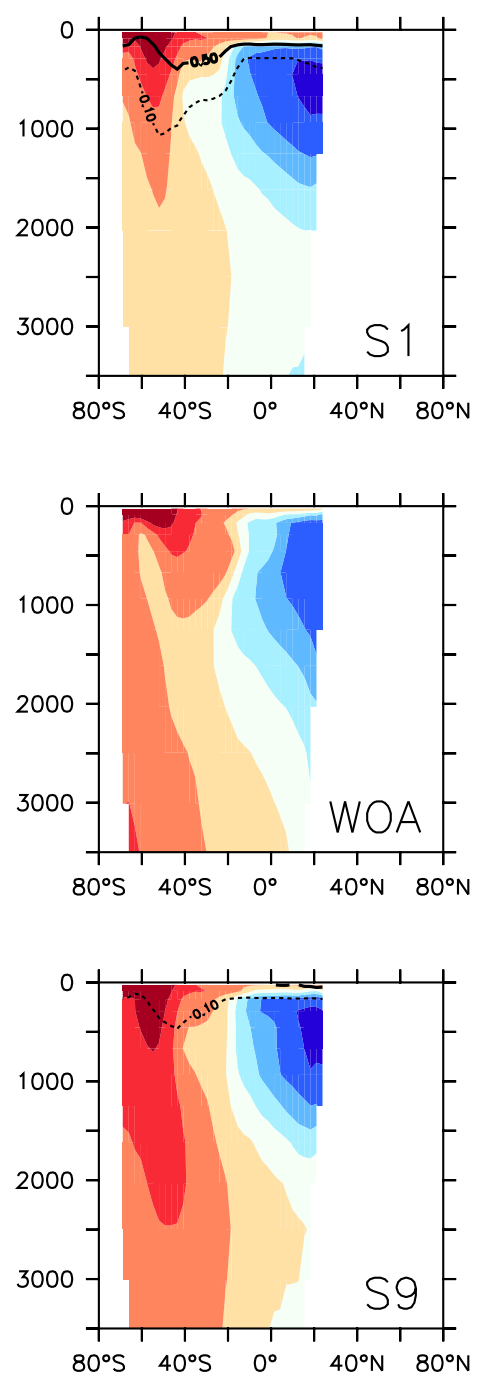

Pacific
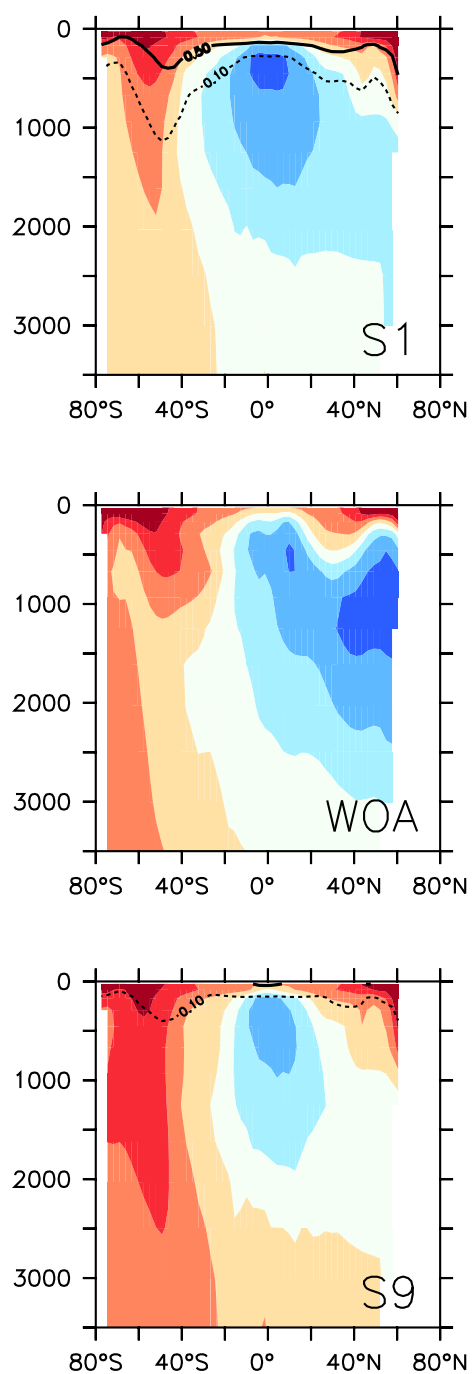

Atlantic
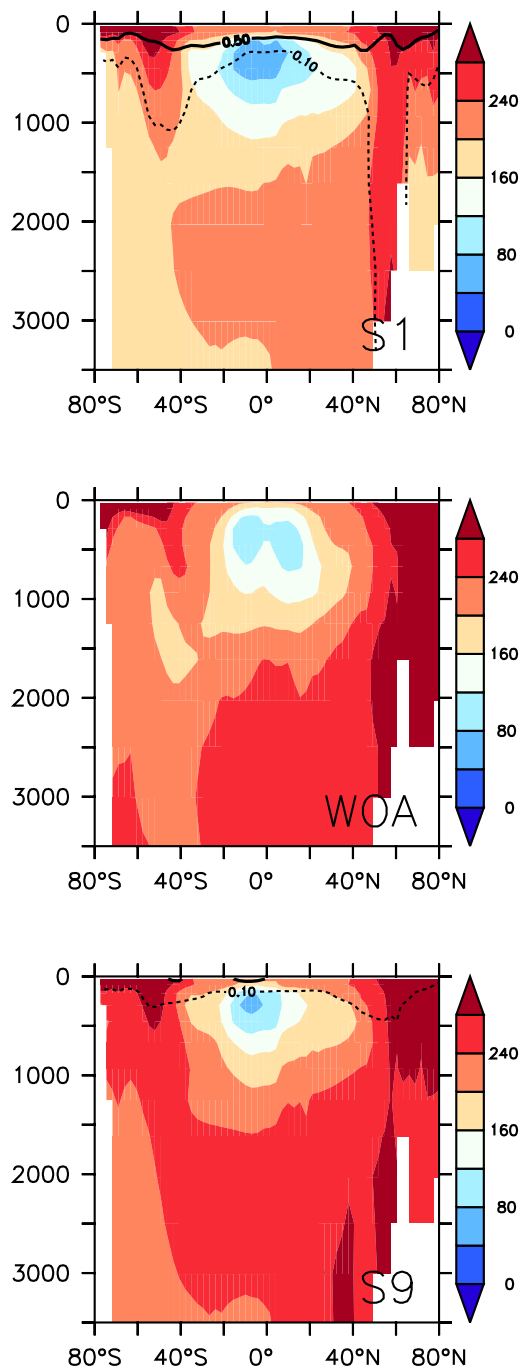

Figure S5. Zonal mean oxygen for three different basins of two sensitivity experiments with RetroMOPS and observations. Upper panels: RetroMOPS with low DOP recycling $\left(\lambda_{\mathrm{s}}=0, \lambda=0.18\right)$. Lower panels: RetroMOPS with high DOP recycling $\left(\lambda_{\mathrm{s}}=0.36, \lambda=0.72\right)$. Mid panels: observations. Contour lines show simulated zonal average DOP (dashed: $0.1 \mathrm{mmol} \mathrm{P} \mathrm{m}^{-3}$. thick: $0.5 \mathrm{mmol} \mathrm{P} \mathrm{m}^{-3}$ ). 
Indian Ocean
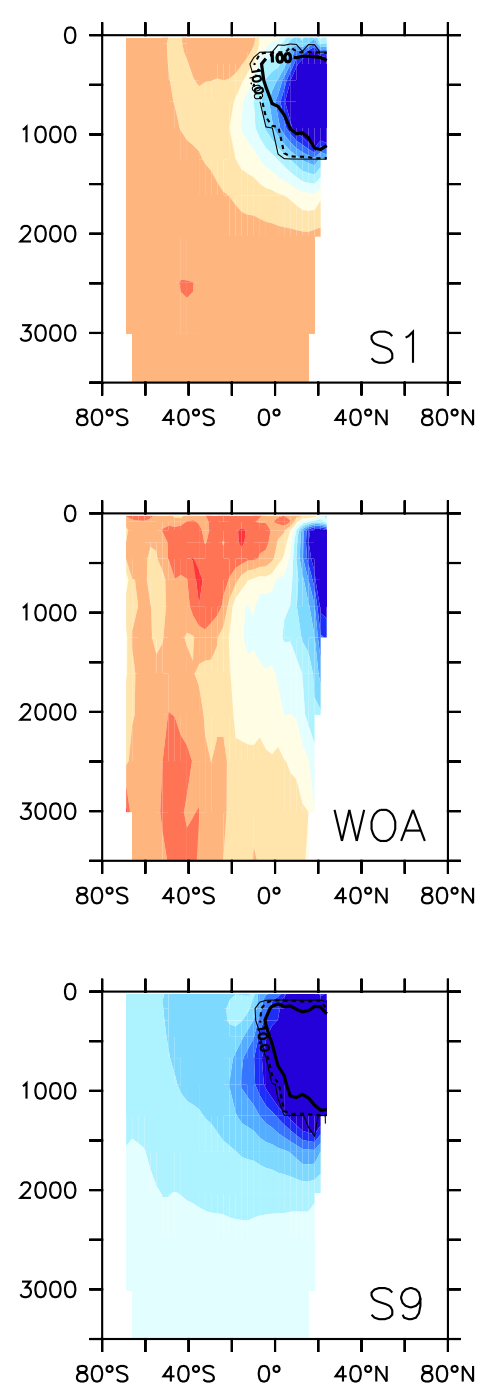

Pacific
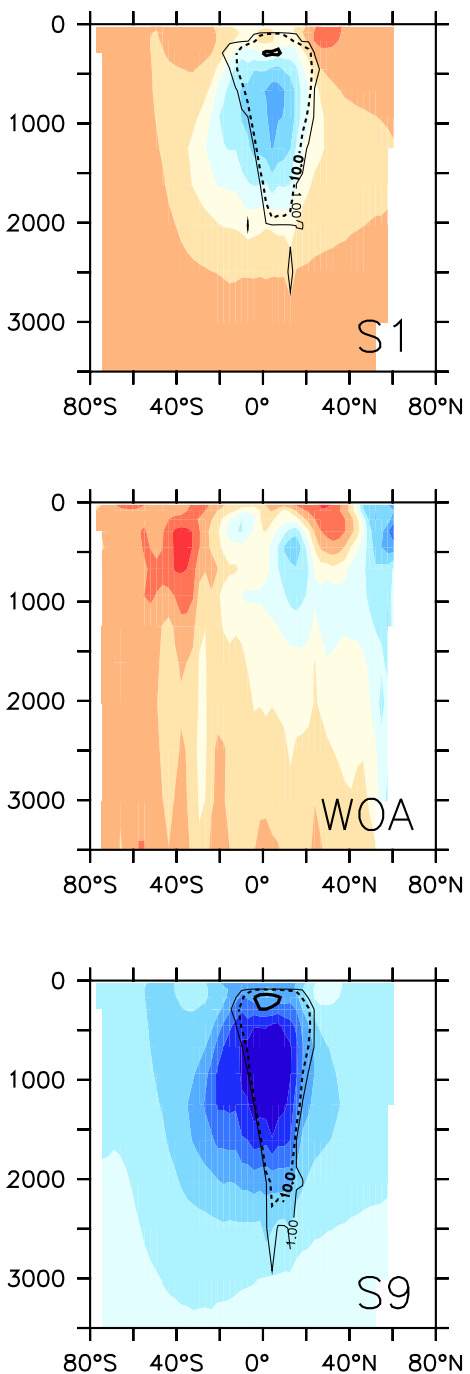

Atlantic
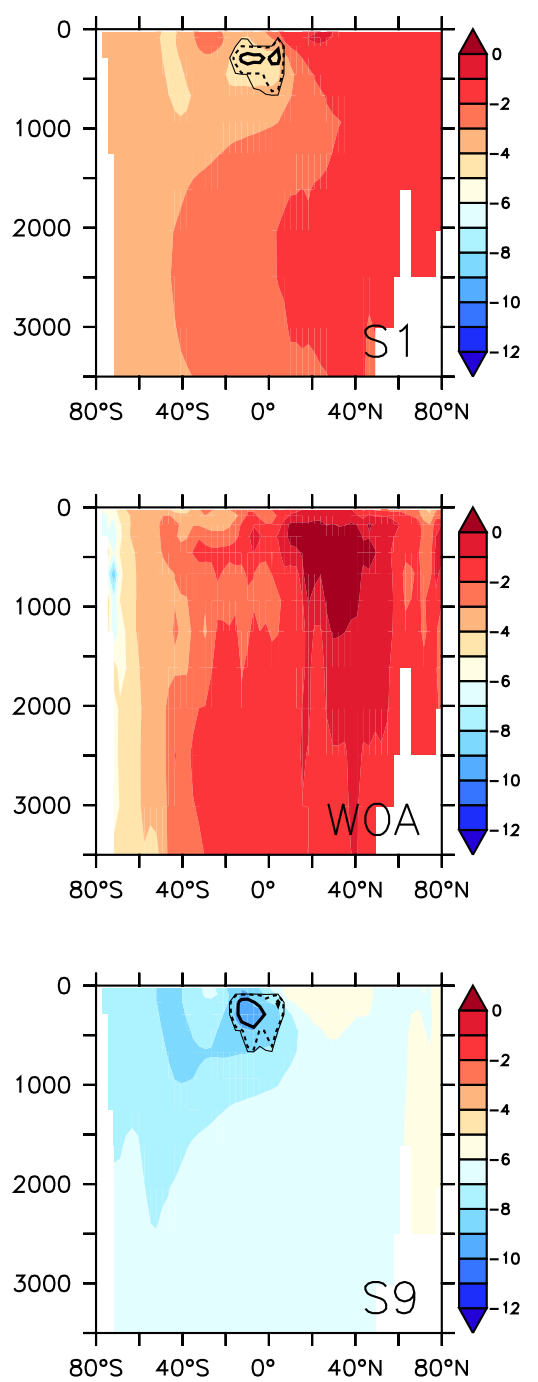

Figure S6. Zonal mean $\mathrm{N}^{*}\left(\mathrm{NO}_{3}-\mathrm{PO}_{4} \times 16\right.$ for three different basins of two sensitivity experiments with RetroMOPS and observations. Upper panels: RetroMOPS with low DOP recycling $\left(\lambda_{\mathrm{s}}=0, \lambda=0.18\right)$. Lower panels: RetroMOPS with high DOP recycling $\left(\lambda_{\mathrm{s}}=0.36\right.$, $\lambda=0.72$ ). Mid panels: observations. Contour lines show simulated zonal average annual fixed nitrogen loss through denitrification (thin: $1 \mu \mathrm{mol} \mathrm{N} \mathrm{m}{ }^{-3} \mathrm{y}^{-1}$, dashed: $10 \mu \mathrm{mol} \mathrm{N} \mathrm{m}{ }^{-3} \mathrm{y}^{-1}$ thick: $100 \mu \mathrm{mol} \mathrm{N} \mathrm{m}^{-3} \mathrm{y}^{-1}$ ). 

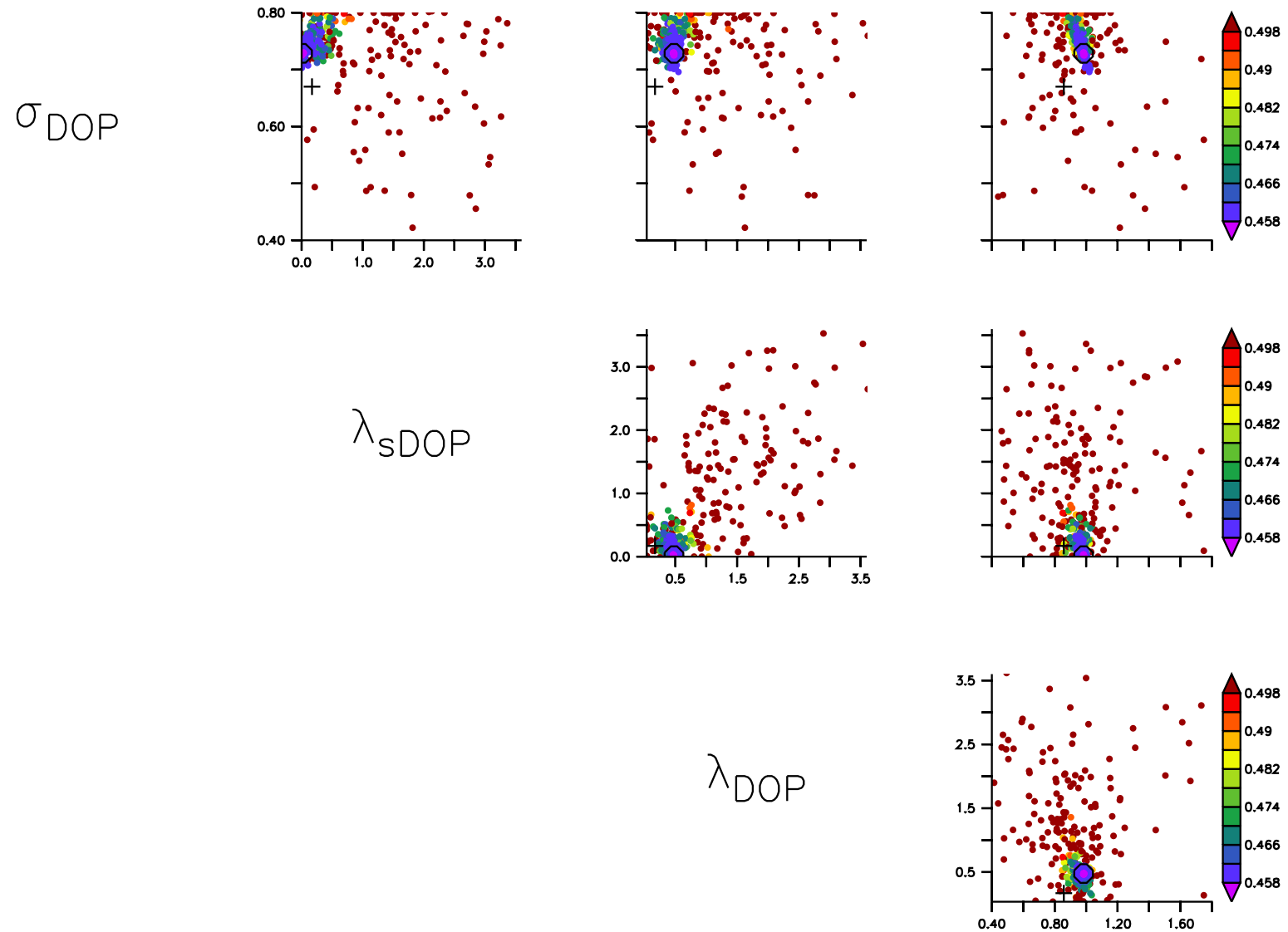

Figure S7. Model misfit, plotted for each pair of parameter combinations of RetroMOPS ${ }^{\circ}$. Colour indicates misfit (see the colour bars on the right). A circle indicates the parameter of one individual of the last generation. For better visibility the parameter range to its boundaries (see Table 1). 